\title{
Presença de Aedes aegypti em Bromeliaceae e depósitos com plantas no Município do Rio de Janeiro, RJ
}

\author{
Presence of Aedes aegypti in Bromeliaceae \\ and plant breeding places in Brazil
}

\author{
Sergio P Cunha, João R Carreira Alves, Milton M Lima, Jair R Duarte, Luiz CV de Barros, \\ José L da Silva, Angelo T Gammaro, Orlando de S Monteiro Filho e Amauri R Wanzeler \\ Gerência de Entomologia da Secretaria Municipal de Saúde do Rio de Janeiro. Rio de Janeiro, RJ, Brasil
}

\section{Descritores}

Aedes. Ecologia de vetores. Insetos vetores. Dengue, transmissão. Dengue, epidemiologia. Bromélias. Aedes aegypti.

\section{Keywords}

Aedes. Ecology, vectors. Insect vectors. Dengue, transmission. Dengue, epidemiology. Bromeliads. Aedes aegypti.

\begin{abstract}
Resumo
Relata-se a freqüência de vegetais Bromeliaceae e de outros criadouros com plantas positivos para Aedes aegypti durante dois ciclos operacionais (tratamento focal) consecutivos no Município do Rio de Janeiro, RJ, cujos períodos foram de 12 de novembro de 2000 a 9 de março de 2001 e 12 de março de 2001 a 15 de junho de 2001. O trabalho destaca as implicações epidemiológicas oriundas da crescente utilização dessas plantas para fins decorativos.
\end{abstract}

\begin{abstract}
The frequency of Bromeliaceae and other plant breeding places where Aedes aegypti can be found is reported during two consecutive operational cycles (focal treatment) in the city of Rio de Janeiro. These cycles took place from November 122000 to March 92001 and from March 122001 to June 15 2001. This study concentrates on the epidemiological implications resulting from the growing use of these plants as decorative living objects.
\end{abstract}

Diversos investigadores relataram o encontro de formas imaturas de Aedes aegypti e Aedes albopictus em Bromeliaceae (Natal et al, ${ }^{5}$ 1997; Forattini et al, ${ }^{1}$ 1998; Forattini \& Marques, ${ }^{2} 2000$; Marques et al, ${ }^{3}$ 2001). Tecem esses autores considerações interessantes sobre as implicações advindas desse encontro para o combate a esses culicídeos.

No Rio de Janeiro, o Programa Diretor de Erradicação do Aedes aegypti, desenvolvido pela Secretaria Municipal de Saúde, face ao aumento significativo do uso dessas plantas para fins decorativos, vem lhes imputando certa importância como criadouros do Aedes aegypti. Em domicílios humanos, é bastante comum o encontro de bromélias em varandas, bem como em quintais (peridomicílio), muitas vezes fixadas em árvores (bromélia epífita), apresentando-se, assim, como oferta para o desenvolvimento de formas imaturas do Aedes aegypti.

O FAD (Sistema de Informações de Febre Amarela e Dengue), programa de computador utilizado pela Fundação Nacional de Saúde em nível nacional para processar dados obtidos nas atividades de campo desenvolvidas pelos agentes de saúde (Ministério da Saúde, ${ }^{4}$ 1998), exclui, no Município do Rio de Janeiro, a bromélia do conjunto de depósitos naturais (a bromélia é considerada criadouro natural quando não há ação antrópica sobre ela [Forattini et $\mathrm{al}^{1}$, 1998; Marques et $\left.\mathrm{al}^{3}, 2001\right]$ ) e a destaca como depósito iso- 
Tabela - Freqüência de Bromeliaceae e de outros criadouros com plantas positivos para Aedes aegypti no Município do Rio de Janeiro durante dois ciclos operacionais consecutivos.

\begin{tabular}{|c|c|c|c|c|c|c|}
\hline \multirow[t]{2}{*}{$\begin{array}{l}\text { Ciclo } \\
\text { operacional }\end{array}$} & \multicolumn{2}{|c|}{$\begin{array}{l}\text { Total de depósitos } \\
\text { com Aedes aegypti }\end{array}$} & \multicolumn{2}{|c|}{$\begin{array}{l}\text { Bromeliaceae com } \\
\text { Aedes aegypti }\end{array}$} & \multicolumn{2}{|c|}{$\begin{array}{c}\text { Depósitos com } \\
\text { plantas, positivos } \\
\text { para Aedes aegypti }\end{array}$} \\
\hline & Urbana & Favela & Urbana & Favela & Urbana & Favela \\
\hline $\begin{array}{l}4^{\circ} \text { ciclo } \\
2000\end{array}$ & 14.335 & 9.111 & 73 & 2 & 7.153 & 3.134 \\
\hline $\begin{array}{l}1^{\circ} \text { ciclo } \\
2001\end{array}$ & 18.847 & 11.553 & 383 & 8 & 9.178 & 3.834 \\
\hline
\end{tabular}

lado, almejando verificar a real importância dessa planta no desenvolvimento do Aedes aegypti.

No quarto ciclo de tratamento focal, que correspondeu ao último ciclo de operações do ano 2000, cujo período se estendeu de 12 de novembro de 2000 a 9 de março de 2001, bem como no primeiro ciclo do ano 2001 levado a efeito de 12 de março a 15 de junho de 2001, o número de Bromeliaceae e de outros criadouros com plantas positivos para Aedes aegypti registrados pelo FAD foi como mostra a Tabela.

Em relação ao total de depósitos com Aedes aegypti, os vegetais Bromeliaceae aparecem com $0,51 \%$ na área urbana e com $0,02 \%$ nas comunidades (favelas), no quarto ciclo operacional do ano 2000 , e com $2,03 \%$ (urbana) e $0,07 \%$ (comunidades), no primeiro ciclo operacional do ano 2001. O aumento no número de bromélias positivas para Aedes aegypti de um ciclo para outro foi devido ao fato de que esses vegetais representam, atualmente, elemento precípuo na composição de paisagismos em condomínios da zona Sul do Município, o que as torna cada vez mais freqüentes nos domicílios humanos. Há evidências de aumento, na área urbana, do número de bromélias com Aedes aegypti no atual ciclo de tratamento focal, iniciado em 18 de junho de 2001.

A diferença entre a positividade de bromélias em área urbana e comunidades foi altamente significante

\section{REFERÊNCIAS}

1. Forattini OP, Marques GRAM, Kakitani I, Brito M, Sallum MAM. Significado epidemiológico dos criadouros de Aedes albopictus em bromélias. Rev Saúde Pública 1998;32:186-8.

2. Forattini OP, Marques GRAM. Nota sobre o encontro de Aedes aegypti em bromélias. Rev Saúde Pública 2000;34:543-4.

3. Marques GRAM, Santos RC, Forattini OP. Aedes albopictus em bromélias de ambiente antrópico no Estado de São Paulo, Brasil. Rev Saúde Pública 33 [On-line] 2001; Disponível em URL http:// www.fsp.scielo.br/rsp no quarto ciclo operacional do ano $2000\left(X^{2}=41,48\right.$; $\mathrm{p}<0,01)$ e no primeiro ciclo do ano $2001\left(X^{2}=217,36\right.$; $\mathrm{p}<0,01$ ), advindo isto do fato de, nas comunidades, essas plantas serem bem menos comuns do que na área urbana.

Também em relação ao total de depósitos positivos, os recipientes com plantas decorativas (vasos, jarros e pratos de sustentação de xaxins que albergam a água provenientes de chuvas ou oriundas de rega) destacaram-se com $49,9 \%$ na parte urbana e com $34,4 \%$ nas favelas, no quarto ciclo (2000), e com $48,7 \%$ na área urbana e $33,19 \%$ nas comunidades, no primeiro ciclo (2001), mostrando o hábito bem comum da população de ter esses depósitos nos domicílios. Como conseqüência desse hábito, os vegetais Bromeliaceae, por ostentar beleza singular, vêm sendo incluídos no conjunto desses depósitos. Cada vez mais, as bromélias são utilizadas de forma doméstica, sem, contudo, ser dada a devida importância ao acúmulo natural de água em seu reservatório (tanque). Por apresentar muitas vezes riqueza de material orgânico em seu conteúdo, a bromélia constitui um micro-habitat do qual podem participar formas imaturas de alguns mosquitos, entre as quais as do Aedes aegypti. Há de se considerar que apenas as bromélias de uso doméstico, ou seja, as que sofreram ação antrópica, teriam certa importância como criadouro desse mosquito, fato que conduz a Secretaria de Saúde a se voltar para o problema.

4. Ministério da Saúde. Secretaria Executiva. Plano Diretor de Erradicação do Aedes aegypti do Brasil. PEAa. Instruções para pessoal de combate ao vetor: manual de normas técnicas. Brasília (DF); 1998.

5. Natal D, Urbinatti PR, Taipe-Lagos CB, Cereti-Junior W, Diederich ATB, Souza RG et al. Encontro de Aedes (Stegomyia) albopictus (Skuse) em Bromeliaceae na periferia de São Paulo, SP, Brasil. Rev Saúde Pública 1997;31:517-8. 